Show simple item record

\title{
Identification of new sources of resistance to Striga gesnerioides in cowpea Vigna unguiculata accessions
}

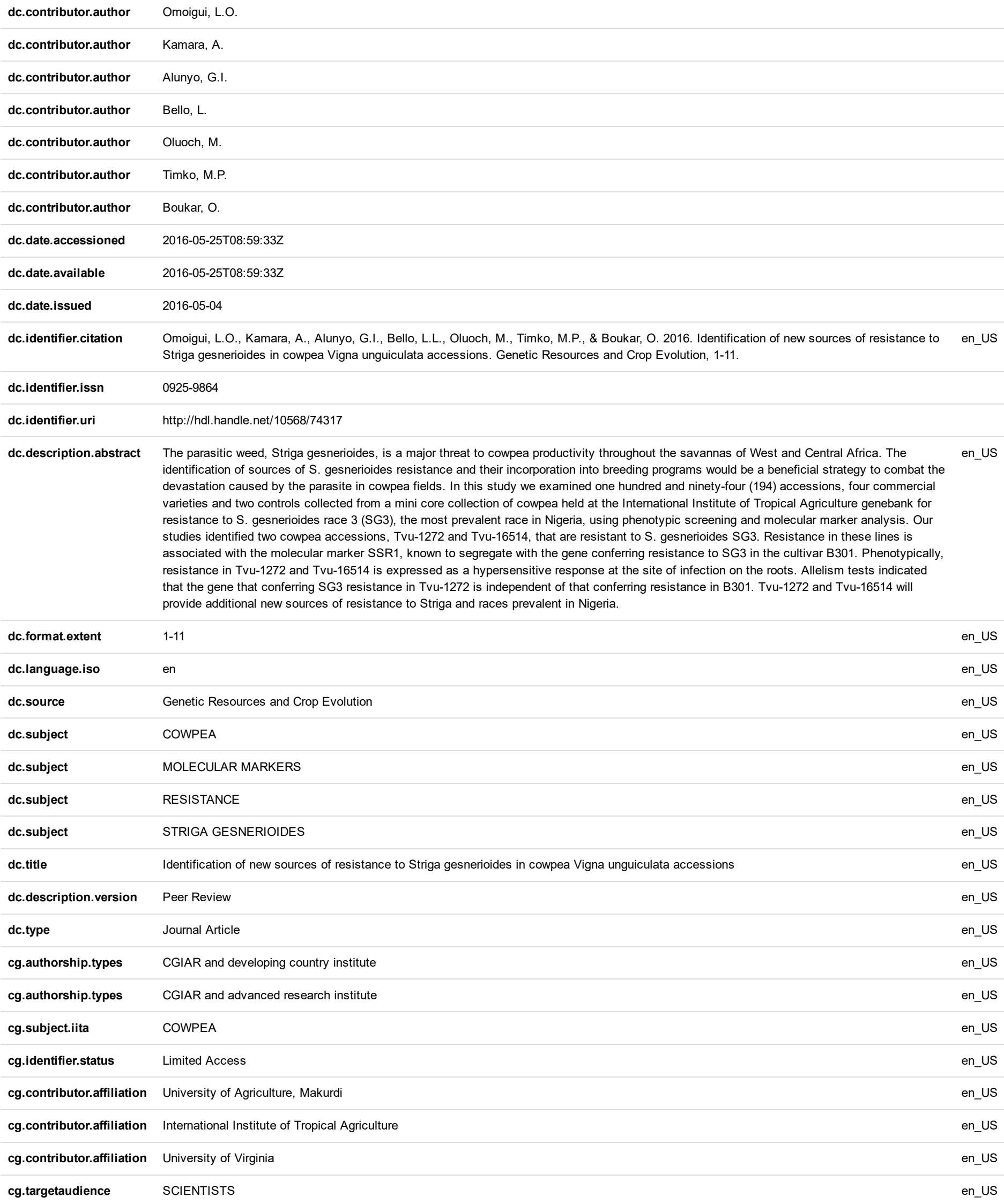




\begin{tabular}{|c|c|c|}
\hline cg.fulltextstatus & Formally Published & en_US \\
\hline cg.identifier.doi & https://dx.doi.org/10.1007/s10722-016-0410-3 & en_US \\
\hline cg.isijournal & ISI Journal & en_US \\
\hline cg.coverage.region & AFRICA & en_US \\
\hline cg.coverage.region & WEST AFRICA & en_US \\
\hline cg.coverage.country & NIGERIA & en_US \\
\hline cg.contributor.crp & GRAIN LEGUMES & en_US \\
\hline
\end{tabular}

\section{Files in this item}

Files Size Format View

There are no files associated with this item.

\section{This item appears in the following Collection(s)}

- IITA Journal Articles [834]

Show simple item record

Show Statistical Information 